management are prescription of medication and referral for psychological therapy. ${ }^{1}$ Having trained in the 1980s we were taught our main strength in managing psychological distress was being there to listen. It was considered a core tool and skill. There is considerable debate about the value of both medication and talking therapy in mild or moderate psychological sadness, so it is a shame this basic asset of a GP is ignored or given no weight of value.

Related to this is the trend now for all sorts of diseases to be 'scored'. In my view, this may distract from the consultation and rarely gives information that is not obtained by normal history taking. In other diseases, such as rheumatoid arthritis, this scoring seems now to be the only outcome of outpatient reviews and highly potent medication is given on that score, not a holistic picture of the patient.

Can we be allowed to practice listening medicine even if we sacrifice QOF points as a result?

\section{John Sharvill,}

Balmoral, Deal, Kent CT14 7EQ.

E-mail: john.sharvill@nhs.net

\section{REFERENCE}

1. Dowrick C. Reasons to be cheerful? Reflections on GPs' responses to depression. Br J Gen Pract 2009; 59(566): 636-637.

DOI: 10.3399/bjgp09X472935

\section{Child and adolescent psychiatry liaison in Ireland}

I am writing from Ireland and have been a GP for the past 12 years; practising for 9 years in Ireland. I did my general practice training in the UK and so have worked in a multidisciplinary setting. However, this is a new phenomenon in Ireland and those that have trained in Ireland find this a difficult concept to grasp.
There is a real fear that their input into patient care will become diluted and undermined. Having trained in the UK, I find it bemusing that this concept is difficult to comprehend. However, it is a positive move as the needs of the patients are becoming complex and well dealt with in a multidisciplinary way.

My letter was inspired after reading the paper on 'GPs' role in the detection of psychological problems of young people." Unfortunately, GPs are finding it difficult to deal with these problems as most of the older teenagers come from unstable family environments and have been in care. The liaison between GPs and the child and adolescent psychiatry team is also not good and each side is suspicious of the other.

I do believe that those of us that have trained in the UK system can contribute positively to overcome these 'suspicions', as working together will keep these patients engaged with health professionals. This will provide a better environment for our young people when they need access to health professionals.

I have to thank the authors for an excellent article and would like to say that they contribute greatly to GPs here in Ireland that want to encourage a multidisciplinary ethos into general practice.

\section{Patricia Black,}

The Surgery, Patrick Street, Mountrath,

County Laois, Ireland.

E-mail: patricias.black@hotmail.com

\section{REFERENCE}

1. Mauerhofer A, Berchtold A, Michaud PA, Suris JC. GPs' role in the detection of psychological problems of young people: a population-based study. $\mathrm{Br} \mathrm{J} \mathrm{Gen}$ Pract 2009; 59(566): e308-314.

DOI: 10.3399/bjgp09X472944

\section{Crisis in the NHS}

I refer to the article by Edin Lakasing and Heather Francis ${ }^{1}$ - may I congratulate you on publishing it.

The article should be compulsory reading for all policy makers in the
Department of Health and for every member of the RCGP and BMA. It is eloquent, accurate, and painfully honest in the way it lays the problems bare. If either of the authors were to stand for election they would have my vote.

\section{Pallavi Devulapalli,} Forest Lodge, The Warren, Shouldham, King's Lynn, Norfolk PE33 ODQ. E-mail: freebird@doctors.org.uk

\section{REFERENCE}

1. Lakasing E, Francis H. Bureaucracy in general practice: time to halt a proliferating malaise. $\mathrm{Br} \mathrm{J} \mathrm{Gen}$ Pract 2009; 59(566): 696-698.

DOI: 10.3399/bjgp09X472953 